\title{
Current Department of Medicine Summary Letters Are Falling Short
}

J Gen Intern Med 37(2):482-4

DOI: $10.1007 /$ s11606-021-06693-w

(C) Society of General Internal Medicine 2021

\section{INTRODUCTION}

In 2013, the Alliance for Academic Internal Medicine (AAIM) developed guidelines for the Department of Medicine (DOM) letter with the goal of providing IM program directors (PDs) with a summary of a student's overall IM performance for residency selection. ${ }^{1}$ Guideline adherence was variable but increased over time and letters using guidelines were more credible. $^{2}$

In 2015, the Association of American Medical Colleges called for revision of the Medical Student Performance Evaluation (MSPE). Revised guidelines recommended inclusion of information on the components of each clerkship grade, component weight, comparison graphs, grade distributions, and unedited performance narratives by evaluators. ${ }^{3}$

In response to the COVID-19 pandemic, AAIM recently offered new guidance for the 2020-2021 residency application season, including recommendations to change the DOM letter by adopting a standardized template. ${ }^{4}$

Little is known about how IM PDs view DOM letters following guidelines or individual components of the DOM letter. ${ }^{5}$ To better understand PDs familiarity with and assessment of guidelines and corresponding DOM letters, we authored five survey questions included in a voluntary survey of IM PDs who completed the 2019 American College of Physicians (ACP) IM In-training Examinationő (2019-IMITEö).

\section{METHODS}

PDs from 577 programs who completed the 2019-IM-ITE were invited to complete a voluntary web survey through a link in their Score Report or email notification from ACP from October 2019 to February 2020. Surveys were completed by 315 PDs. After excluding 45 respondents who opted out and 19 respondents from non-US programs, the dataset included 251 respondents. The survey consisted of multiple-choice and 5 -point Likert scale questions.

Received October 7, 2020

Accepted February 28, 2021

Published online April 28, 2021
To assess statistical representativeness of the responses, self-reported program size and US Census region were compared to the US/US territory-based population of IM programs using data from the Accreditation Council for Graduate Medical Education. ${ }^{6}$ Responses were dichotomized for items regarding familiarity to allow for a secondary analysis comparing those who had heard of guidelines even if not entirely familiar with them. Responses were compared for goodnessof-fit to program size and region using the adjusted Wald (Pearson) chi-square statistic. Data analysis was conducted in Stata 16.2. The study was exempted by the University of Chicago IRB (IRB20-1108).

\section{RESULTS}

PDs were asked how familiar they are with AAIM DOM letter guidelines. Most $(84 \%$; 211/251) indicated some degree of familiarity whereas $16 \%$ were not familiar. Of PDs familiar (Table 1), most (82\%) reported receiving DOM letters following guidelines "very often/often" (37\%) or "sometimes" (49\%). Larger programs (> 100 residents) reported receiving letters that "often" followed guidelines at a higher rate than medium-sized or smaller programs $(p=0.032)$.

PDs familiar with the guidelines were asked whether letters following them were more useful in discriminating among candidates. Thirty-six percent reported these letters were more useful; $25 \%$ believed they were not; and 39\% were undecided. Nearly all (92\%) reported some degree of redundancy between DOM letters and the MSPE.

PDs familiar with the guidelines were asked what additional information might be useful to include on a DOM letter. More than half indicated adding a distinguishing feature that makes the student more likely to be successful in an IM residency (56\%) and sub-internship performance (55\%) would be useful; $45 \%$ selected shelf-exam scores (Table 2). There were no statistical associations between those items when compared by program size or region.

\section{DISCUSSION}

Most PDs reported some degree of familiarity with DOM guidelines and to receive DOM letters that follow guidelines. Yet, even among letters that follow guidelines most PDs found DOM letters to some extent redundant to the MSPE. Our study 
Table 1 Representativeness of the Survey Responses and Responses, Familiarity with CDIM-APDIM Guidelines for DOM Letters, and Frequency of Receiving DOM Letters that Follow Guidelines

\begin{tabular}{|c|c|c|c|c|c|}
\hline \multirow[t]{2}{*}{ US Census region* } & \multicolumn{5}{|c|}{ Program size (self-reported number of residents), $n$ (column \%) } \\
\hline & $<25(n=46)$ & $25-50(n=103)$ & $51-100(n=67)$ & $\begin{array}{l}\text { Over 100 } \\
(n=35)\end{array}$ & $\begin{array}{l}\text { Total }(n= \\
\text { 251) }\end{array}$ \\
\hline Northeast & $6(13)$ & $24(23)$ & $28(42)$ & $13(37)$ & $71(28)$ \\
\hline Midwest & $16(35)$ & $23(22)$ & 13 (19) & $8(23)$ & $60(24)$ \\
\hline West & $12(26)$ & $26(25)$ & $11(16)$ & $7(20)$ & $56(22)$ \\
\hline Program size (self-reported & \multicolumn{5}{|c|}{ Familiarity with CDIM-APDIM guidelines for DOM letters, $\boldsymbol{n}$ (column \%) } \\
\hline number of residents) ${ }^{\dagger}$ & $\begin{array}{l}\text { Familiar }(n= \\
\text { 211) }\end{array}$ & $\begin{array}{l}\text { Not familiar } \\
(n=40)\end{array}$ & Total $(n=251)$ & $p$ value ${ }^{*}$ & \\
\hline $51-100$ & $63(3)$ & $4(10)$ & $67(27)$ & 0.012 & \\
\hline Over 100 & 35 (17) & $0(-)$ & $35(14)$ & 0.049 & \\
\hline Program size (residents) in two & \multicolumn{5}{|c|}{ Frequency of receiving DOM letters that follow guidelines, $n$ (row \%) } \\
\hline categories & Often $(n=79)$ & $\begin{array}{l}\text { Sometimes }(n= \\
\text { 103) }\end{array}$ & $\begin{array}{l}\text { Does not receive letters that follow } \\
\text { guidelines }(n=29)\end{array}$ & $\begin{array}{l}\text { Total }(n= \\
\text { 211) }\end{array}$ & $p$ value* \\
\hline Over 100 & $20(25)$ & $14(14)$ & $1(3)$ & $35(17)$ & 0.032 \\
\hline Less than 100 & $59(75)$ & 89 (86) & $28(97)$ & $176(83)$ & \\
\hline
\end{tabular}

Bolded entries represent values that are statistically significant

* Data from six programs in US unincorporated territories are included in the totals above but characteristics for those programs are excluded to ensure anonymity

${ }^{I}$ Program size and Census region were compared to the population of all US IM programs using data from the Accreditation Council for Graduate Medical Education (ACGME) - Accreditation Database System (Public) and US Census Bureau regions as of the 2018-2019 Academic Year. $p$ values for all 20 two-sample tests of proportions (four program sizes by five Census regions) were above an alpha level of 0.01 (99\%)

tp value at alpha level 0.05/adjusted Wald (Pearson) chi-square (1 degree of freedom). Sources for ACGME program data ${ }^{6}$ and US Census region https://www2.census.gov/geo/pdfs/maps-data/maps/reference/us_regdiv.pdf

is a cross-sectional survey and is not necessarily generalizable over time and to all programs.

Writing DOM letters is time-consuming and reading letters that do not add value is time-wasting. Most importantly, providing PDs with information that does not enhance their ability to select residency applicants is a missed opportunity. This research provides data about what additional information IM PDs might prefer as

Table 2 Useful Additional Information, If Any, Identified by Program Directors for Inclusion on a Department of Medicine Letter

\begin{tabular}{ll}
\hline \hline & $\boldsymbol{n ( \% )}$ \\
\hline $\begin{array}{ll}\text { Opportunity to add a distinguishing feature that makes the } \\
\text { student likely to be successful in an Internal medicine }\end{array}$ & 119 \\
residency & $(56)$ \\
Sub-internship performance & 117 \\
& $(55)$ \\
Medicine shelf exam & $96(45)$ \\
More text from faculty evaluations & $87(41)$ \\
Grades of all IM clerkship assessment components (not just & $66(31)$ \\
final grade) & $52(25)$ \\
4th year medical elective performance & $35(17)$ \\
More description of student career interests & $33(16)$ \\
Electives to be taken in the Department of Medicine during & \\
the senior year & $13(6)$ \\
More description of student extracurricular activities & $7(3)$ \\
More description of student research experience & $7(3)$ \\
Other & $29(14)$ \\
No additional information would be useful to include & $(n=$ \\
US Programs with PD's familiar with AAIM DOM letter & $211)$ \\
guidelines &
\end{tabular}

Respondents were allowed to select one or more items; total percentages exceed 100

Tests for over-correlation between items reported in table above. Lawley chi-square (65 degrees of freedom): 431.95; $p<0.001$; adjusted likelihood ratio chi-square (66 degrees of freedom): 409.29; $p<0.001$. Alpha level for both tests: 0.05 they review applications. Providing more text from faculty evaluations not included in MSPE and an applicant's distinguishing feature may further help programs identify best "fit" between applicant and program.

As we move forward to a unique application season during COVID-19, it is more important than ever that we provide value in our DOM evaluations and consider adopting the new AAIM 2020-2021 DOM letter recommendations. ${ }^{4}$

Acknowledgements: We thank the American College of Physicians for including our survey questions on the 2019 Internal Medicine InTraining Examinationô Program Directors Questionnaire and for sharing the data with us for analysis. We also thank the Alliance for Academic Medicine and the Clerkship Directors in Internal Medicine Survey and Scholarship Committee for its assistance with editing the survey questions.

Diane Levine, $M D^{1}$

Jeffrey S. LaRochelle, MD, MPH ${ }^{2}$

Michael Kisielewski, $M A^{3}$

Linda Harris, $A A S^{4}$

Amber T. Pincavage, $M D^{5}$

${ }^{1}$ Department of Internal Medicine, Wayne State University,

Detroit, MI, USA

${ }^{2}$ Department of Medical Education, University of Central Florida College of Medicine,

Orlando, FL, USA

${ }^{3}$ Alliance for Academic Internal Medicine,

Alexandria, VA, USA

${ }^{4}$ Research Center American College of Physicians, Philadelphia, PA, USA 


\section{${ }^{5}$ Department of Medicine, University of Chicago,} Chicago, IL, USA

Corresponding Author: Diane Levine, MD; Department of Internal Medicine, Wayne State University, Detroit, MI, USA (e-mail: dllevine@med.wayne.edu).

Author Contribution All authors had full access to all of the data in the study and take responsibility for the integrity of the data and the accuracy of the data analysis.

Concept and design: Levine, LaRochelle, Pincavage

Acquisition, analysis, or interpretation of data: All authors

Drafting of the manuscript: Levine, Kisielewski, Pincavage

Critical revision of the manuscript for important intellectual content:

Levine, LaRochelle, Kisielewski, Harris, Pincavage

Statistical analysis: Kisielewski, Harris

Administrative, technical, or material support: Kisielewski, Harris

All authors approved the manuscript and agree to adhere to all terms outlined in Journal of General Internal Medicine.

\section{Declarations:}

Conflict of Interest: The authors declare that they do not have a conflict of interest.

\section{REFERENCES}

1. Lang J, Aboff BM, Bordley DR, Call S, Dezee KJ, Fazio SB, et al. Guidelines for writing department of medicine summary letters. Am J Med. 2013; 126(5):458-63.

2. Fitz M, La Rochelle J, Lang V, DeWaay D, Adams W, Nasraty F. Use of standard guidelines for Department of Medicine summary letters. Teach Learn Med. 2018;30(3):255-65.

3. Association of American Medical Colleges (AAMC). Recommendations for Revising the Medical Student Performance Evaluation (MSPE). 2017. Available at https://www.aamc.org/system mspe-recommendations.pdf. Accessed July 1, 2020.

4. Alliance for Academic Internal Medicine (AAIM). AAIM Recommendations for the 2020-2021 Internal Medicine Residency Application Cycle in Response to the COVID-19 Pandemic. 2020. Available at https://www. im.org/resources/ume-gme-program- resources/resources-residency-application2021. Accessed July 1, 2020.

5. 2018 NRMPő Program Director Survey: what do Program Directors like to see?. Available at 2018 NRMPő Program Director Survey: What do Program Directors like to see? Available at https://blog.matcharesident.com/tag/ program-director-survey/ Accessed November 20, 2020.

6. Accreditation Council for Graduate Medical Education (ACGME). ACGME Accreditation Database System Public. Available at https://apps.acgme. org/ads/Public/Programs/Search. Accessed December 1, 2019.

Publisher's Note: Springer Nature remains neutral with regard to jurisdictional claims in published maps and institutional affiliations. 